\title{
Review on Genetic and Breeding for Low -N tolerance in Maize
}

\author{
Belay Garoma ${ }^{1} \quad$ Sinatyehu Alamirew ${ }^{2} \quad$ Temesgen Chibsa ${ }^{1}$. \\ 1.Bako National maize research/EIAR, Bako, \\ 2.Jimma University, Jimma, Ethiopia
}

\begin{abstract}
Low soil nitrogen (Low N) is one of the major abiotic stresses causing maize yield reduction in tropics of Africa. However, genetic variation observed under low $\mathrm{N}$ and crossing among adaptive/NUE elite lines should be targeted for different secondary traits, economic disease and inheritance studies breeding for Low $\mathrm{N}$ in maize. In addition, breeding for Low $\mathrm{N}$ and drought have common traits indicating that common adaptive mechanism and thus, appear to develop maize genotypes that tolerance to stress and such maize genotypes exhibited high yield performance under low and high $\mathrm{N}$ condition across environments, is likely good for subsistence farmers in Africa for maize production. Multiple QTLs detected under Low N and high-nitrogen conditions for grain yield per plant, secondary and physiological traits. However, a direct use of these detected QTLs has been less achieved breeding for Low N tolerance in maize program, because of eQTLs. Thus, stable QTLs should be validated and fine mapping or GWAS method should detect the candidate genes for controlling NUE for low soil nitrogen in maize.
\end{abstract}

Keyword: Low N, secondary traits, genotypes, NUE, QTLs

DOI: $10.7176 / \mathrm{JNSR} / 12-1-04$

Publication date: January $31^{\text {st }} 2021$

\section{Introduction}

Maize (Zea mays L.) is a worldwide important stale crop for food, feed and industry. Despite the importance of maize as a principal food crop particularly in developing country, its average yield in Africa (2.02 $\left.\mathrm{tha}^{-1}\right)$ is still low as compared to the world average (5.57 t ha-1) (FAO,2017). A significant portion of this yield gap is attributable to biotic and abiotic stresses. Among abiotic factors such as drought and low levels of soil nitrogen (low $\mathrm{N}$ ) are the most important maize production constraints in tropics of Africa. Nitrogen deficiency can cause several adverse effects on maize growth, development and final yield. Cai et al., (2012) reported that nitrogen deficiency can cases stunting plant, reduction of leaf area, increasing silking interval and decreasing chlorophyll content and other physiological activities. Annual grain yield losses estimate range between 10 to $50 \%$ due to Low $\mathrm{N}$ stress in soil of tropic (Noelle et al., 2017). Even the damage is high if $\mathrm{N}$ stress occurs just before flowering when the physiological process determine yield.

Low soil fertility and limited application of nitrogen fertilizers have impact on maize production. Particularly, it is high proportion in the areas of lowland and mid-altitude agro- ecologies of tropics where maize is cultivated by small scale farmer under low nitrogen conditions (Bänziger et al., 2004). Recommended application of inorganic fertilizer N source like UREA in sub-Saharan Africa is low due to the limited resource of subsistence farmers and low availability, particularly during main cropping season (Bänziger et al., 2004). In other word, farmers applied $\mathrm{N}$ at below the optimum recommendation. Addition, high rain fall lead to leaching soil nitrogen around plant root zone resulted in N stress (Bello et al., 2011). Similarly, Continuous cultivation of maize as a mono-cropping contributed to rapid depletion of soil nitrogen. All these factors could be worsen $\mathrm{N}$ stress and thus, taken to consideration breeding for low $\mathrm{N}$ stress in maize. Maize genotypes differ in nitrogen up take and utilization for grain yield and related traits under Low-N condition and thus, an opportunity to develop maize variety tolerance to $\mathrm{N}$ stress and subsequently to increase maize productivity. Therefore, the objective of this paper was to review the genetic bases breeding for Low $\mathrm{N}$ tolerance, statues of maize breeding under Low N stress and QTLs detected for important traits under Low $\mathrm{N}$ and optimum conditions were reviewed.

\section{Genetic bases breeding for Low $\mathbf{N}$ tolerance in maize}

Genetic studies have been reported on maize genotypes under low $\mathrm{N}$ using different sources of germplasm. However, the information on gene action conditioning grain yield of tropical maize under low $\mathrm{N}$ has been contradictory. For example: non-additive genetic effects influenced grain yield under low N (Meseka et al., 2013) suggesting that it support epistasis theory and specific combining ability and subsequently to develop maize hybrids for low $\mathrm{N}$ tolerance whereas, other reported that additive genetic effects control grain yield under low $\mathrm{N}$ stress. In contrast, other reported that both additive and non-additive genetic effects were important in determining the inheritance of grain yield of maize under low N. Similarly, both additive and non-additive gene effects are the most important in both $\mathrm{N}$ conditions, while non-additive gene effects are less important under low-N stress (Tesfaye et al., 2019). Thus might be due to the $\mathrm{N}$ stress level and testing environments under which the genotypes were evaluated and being their difference among genotypic used in the studies (Mosisa, 2008). 


\section{Important secondary traits under Low $\mathbf{N}$ tolerance}

Secondary traits can increase the efficiency of selection for grain yield under Low N. Multiple traits including morphological characteristics, physiological, biochemical characteristics and other are associated with yield under Low $\mathrm{N}$ tolerance in maize (Cai et al.., 2012). Yield reduction under low $\mathrm{N}$ stress is due to increased kernel abortion and fewer kernels per ear (Below 2002) (Fig. 1), suggesting that ear and grain development is highly affected by $\mathrm{N}$ deficiency. Similarly, as anthesis-silking interval increased and chlorophyll content decreased.

Secondary traits; ears per plant and leaf senescence showed the main discriminated high-yielding genotypes (Benziger and Lafitte, 1997), .picture 2). Prolonged stay green in leaves and deep root contributed for yield increase under Low $\mathrm{N}$ condition.

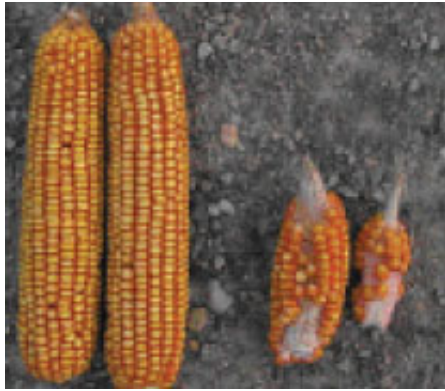

Figure 1 Ears per plant to be selected under Low N. ears at left selected (Below, 2002).

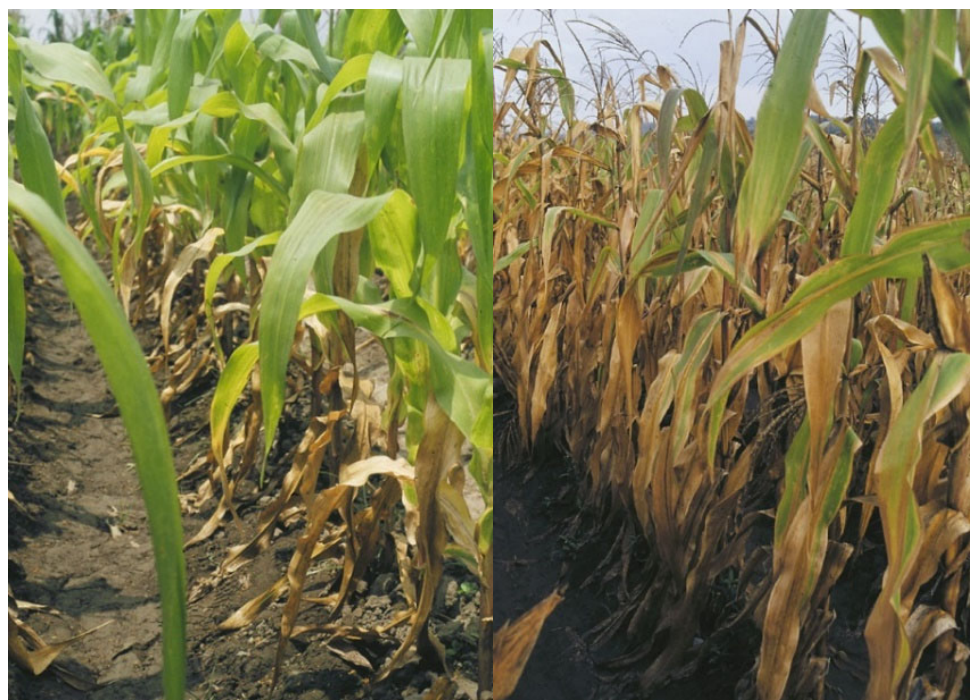

Figure 2 Leaf senescence under N stress. Genotype at left side selected under Low N condition (Benziger, 1997)

\section{Breeding for Low $\mathbf{N}$ tolerance in maize \\ Source of germplasm for Low $\mathbf{N}$ tolerance}

Genetic variation (divers' germplasm) and breeding approach can efficiently improve breeding for low $\mathrm{N}$ tolerance in maize. Adaptive parents, NUE parents, open pollinated varieties and others can as source of materials for breeding under low $\mathrm{N}$ and drought stresses. Crossing among adaptive/NUE elite lines to be targeted for different secondary traits, economic disease and inheritance studies. For example: NUE by drought tolerance for most secondary traits, Low $\mathrm{N}$ tolerance by drought tolerance, Low $\mathrm{N}$ tolerance by disease resistance, Low $\mathrm{N}$ tolerance by NUE and NUE by susceptible for inbred lines development. Notice that the current trend of inbred line development in maize is shifted from recurrent selfing to double haploid breeding technology by CIMMYT. Doubled haploidization (DH) is a technique of doubling the chromosome number of a haploid cell. It is the fast breeding program since it enhance for the production of homozygous lines within short period of time and DH lines developed (Segui-Simmarro, 2015).

Several studies conducted on segergant families, inbred lines and recurrent selection evaluation under Low $\mathrm{N}$ and drought conditions. For instance, one hundred maize inbred lines were evaluated under Low $\mathrm{N}$ and drought and 15 inbred lines showed high tolerance to drought. Also, tolerance inbred lines showed shorter ASI, low canopy temperature, lower drought susceptibility index, higher chlorophyll content and comparatively higher grain yield when subjected to drought stress (Shadakshari and Shanthakumar, 2015). Similarly, Meseka et al., (2006) evaluated 24 inbred lines under drought and Low soil $\mathrm{N}$ conditions (depleted over several years without $\mathrm{N}$ fertilizer application) and 12 inbred lines showed that tend to tolerance drought and Low N, also, two inbred lines performed 
under optimum and Low $\mathrm{N}$ condition. Such inbred lines are helpful for future breeding program under two conditions.

\section{Recurrent selection under Low $\mathbf{N}$ tolerance}

Recycling from full and half sibs' families and recurrent selection has been used to improve yield and other agronomic traits. Evaluation and selection of different cycles (S1 to S3) revealed that desirable traits can be combined and changed in gene frequencies enable to enhance the yield and other traits under Low soil $\mathrm{N}$ in maize. Ajala et al., (2012) reported that three population were recycled three time through recurrent selection and showed that yield gain over $200 \mathrm{~kg} / \mathrm{ha} /$ cycle under $30 \mathrm{~kg} \mathrm{~N} / \mathrm{ha}$ and over $270 \mathrm{~kg} / \mathrm{ha} /$ cycle under $90 \mathrm{~kg} \mathrm{~N} / \mathrm{ha}$, this might be due to favorable alleles combined to improve agronomic performance under stress and optimum conditions. Similarly, yield gains under low $\mathrm{N}$ due to recurrent selection also found for drought tolerance in maize populations (Lafitte et al., 1997).

\section{Evaluation of maize germplasm under Low $\mathbf{N}$ tolerance}

It is obvious that an experimental site for Low $\mathrm{N}$ depleted by continuous planting of heavy feeder crop like sorghum until the leaves showed typical N deficiency symptoms or Low N site could be depleted by growing unfertilized, non-leguminous crops for several seasons. Depending on breeder objective, soil samples might be taken and analyzed for different soil nutrient properties. During planting, like DAP should be applied meanwhile N sources like UREA not applied during experiment conducted.

Breeding for stresses (Low N and drought stress) tolerances in maize, selection can be either directly under stress or indirect under optimum or both conditions. Studies reported that some maize genotypes showed a good performance under Low $\mathrm{N}$ and drought stress condition, this might be both have common adaptive mechanism and some traits contributed under both stress. Maize population improved through recurrent selection showed that tolerance to drought also resulted tolerance to low soil nitrogen conditions (Zambesi and Mwambula, 1997). Similarly, improvement for drought tolerance also resulted in performance under low $\mathrm{N}$ conditions (Banziger et al., 1999). This might be due to selection for flowering time (ASI), leaf senescence and ear per plant are common traits that contribute for yield under both conditions. If yields in the target environment (example $4 \mathrm{t}$ per ha, yield under low $\mathrm{N}$ is nearly equal to two third of optimum $\mathrm{N})$ and yields obtained under well-fertilized conditions $(6 \mathrm{t}$ /per ha), maize germplasm should be evaluated under severe N stress as part of selection (Bänziger et al. 1997). However, other studies reported that Low-N stress reduced yield by $64 \%$ and $58.2 \%$ as compared to high-N conditions across environments (Tesfaye, et al., 2019), Thus, might be due to genetic variability in maize and degree of $\mathrm{N}$ depletion for different experimental fields (Worku et al., 2008).

A wide range of studies have reported the presence of genetic variability (inbred lines, maize hybrids and $\mathrm{OPV}$ ) in $\mathrm{N}$ efficiency, under low-N, drought and optimum conditions. Maize hybrids were evaluated across optimum and low-N, well-watered and managed drought-stress showed that difference among hybrids for grain yield (Nyombayir et al., 2011) and additive genes effect for grain yield, ear per plant and ASI were more important than non-additive gene action. In contrast, Noëlle et al., (2017) evaluated maize hybrids under high and Low N soil conditions and found that non-additive gene (SCA) effect influenced grain yield under low soil and thus an opportunity to develop hybrid development, whereas, additive gene (GCA) effect influenced grain yield under high soil nitrogen $\mathrm{N}$ conditions. Tesfaye et al., (2019) evaluated 48 maize hybrids that difference among genotypes for most traits and additive and non-additive gene effect more important under both conditions. Likewise, Weber et al., (2012) evaluated 174 trials over nine years and found that heritability was highest under optimal conditions and lowest under random abiotic stress suggested that low selection and genetic gain under stress condition. The author reported that elite maize hybrids tolerant to random abiotic stress can be most efficiently selected under optimal and/or low-N conditions while low-N tolerant genotypes should be selected directly under low $\mathrm{N}$.

Genotypes could be differences in Nitrogen use efficiency (NUE) in Guohua 2007. NUE is defined as dry matter yield produced per unit of $\mathrm{N}$ supplied and available in the soil. NUE can be: N-uptake efficiency from soil and utilization of $\mathrm{N}$ to produce grain yield (Sinclari and Vadez 2002). The efficiency of $\mathrm{N}$ uptake also likely related to variability in the architecture of root system. Cereals in utilization of $\mathrm{N}$ and to produce grain yield depends on multiple processes, including root system to uptake $\mathrm{N}$, translocation of reduced $\mathrm{N}$ to the leaves, and remobilization of $\mathrm{N}$ from stalks and leaves to produce grains (Niu et al., 2007). Similarly, N-efficient maize hybrids had a higher net photosynthetic rate at the kernel filling stage hence slow leaf senescence and result in performed to drought and Low soil N conditions. Maize genotypes evaluated under low-N and high-N levels and showed that genetic difference in grain yield under low-N and high $\mathrm{N}$ due to $\mathrm{N}$ utilization and uptake, whereas other showed some hybrids evaluated and out yielded under both low-N and high-N conditions (Worku et al., 2007).

Maize hybrid nitrogen use efficiency performance is determined by the plant ability to take up nitrogen from soil, the physiological capacity process, partition $\mathrm{N}$ to the grain and sink strength to set kernels under high and Low N conditions. Mastrodomenico et al., (2017).evaluated 265 maize hybrids under Low N and $252 \mathrm{~kg} \mathrm{~N}$ ha-1 (optimum N) conditions across eight environments for five years and showed that only 5 hybrids found yields 
ranked in the top $10 \%$ for both $\mathrm{N}$ conditions. Moreover, one hybrid (ICI740 $\times$ PHK56) exhibited high yield performance under low and high $\mathrm{N}$ conditions (figure 3).
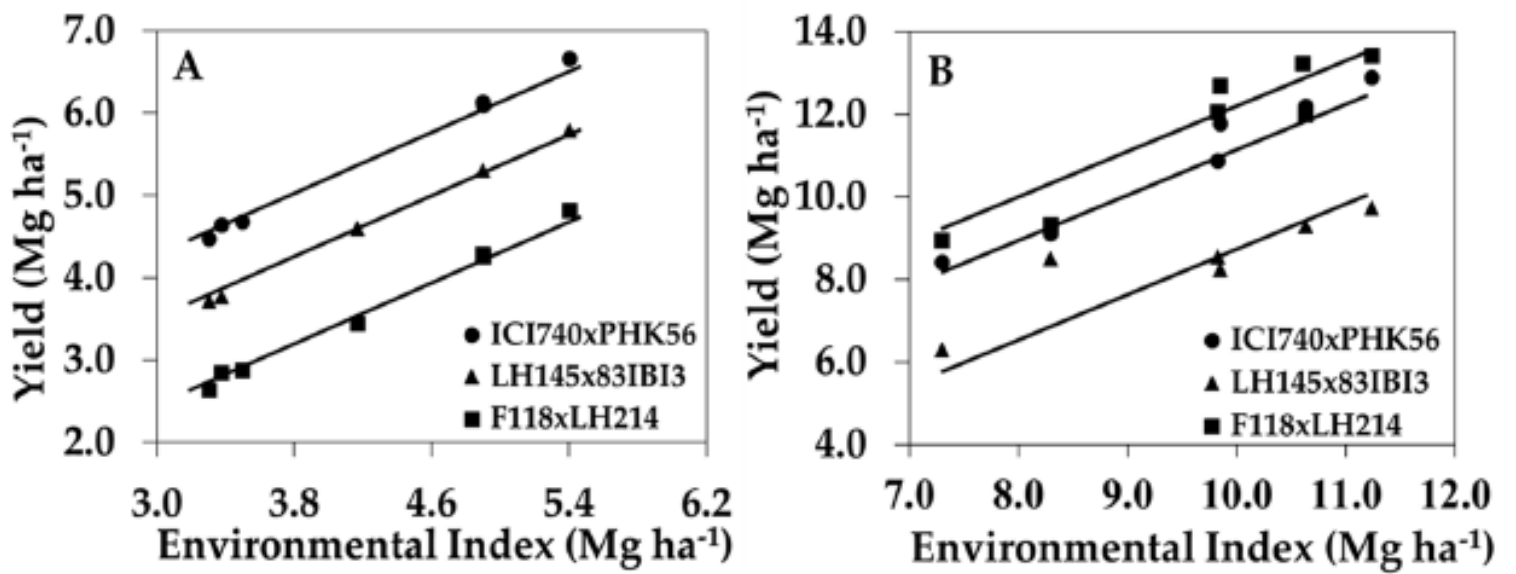

Figure 3. Yield of select hybrids across environmental indices when grown with $\mathrm{A})$ low $\mathrm{N}(0 \mathrm{kgN}$ ha-1), and B) high N (252 kg N ha-1 source. Mastrodomenico et al., 2017

Application of DNA markers and Quantitative traits locus (QTL) for breeding Low N tolerance in maize Molecular marker or DNA marker is defined as a particular segment of DNA sequence on known chromosome location for particular genes or specific trait. Currently, SSR; SNP and DArT markers are commonly used in plant breeding. Thus, it can be applied for different objective of breeding program under different environment conditions.

Quantitative traits locus (QTL) is link to phenotypic data (traits measurement) and genotype data using molecular marker that attempt to explain the genetic basis of variation in traits. QTL mapping is includes the development of mapping population for stress tolerance related traits, identification of markers, genotyping the mapping population with polymorphic markers, constriction of genetic map, phenotpying traits and QTL mapping using genotypic and phenotypic data (Chamarthi et al., 2011). QTL mapping is applied for trait of interest and under different conditions.

\section{QTL mapped for yield and important traits for Low $\mathbf{N}$ and optimum conditions}

Low $\mathrm{N}$ tolerance is a complex trait that is influenced by genetics and environmental and genotype by environment interaction. This means that Low $\mathrm{N}$ tolerance is a complex quantitative trait in maize that controlled by many genes and it also affected by genotype $\mathrm{x}$ environment interaction. Low $\mathrm{N}$ tolerance has been associated with morphological characteristics, yield and yield components, and physiological and biochemical characteristics (Cai et al. 2012). Thus, their genetic basis dissected using marker. Several quantitative trait loci (QTLs) for multiple traits under Low and optimum $\mathrm{N}$ conditions have been identified in maize. 58 QTLs detected under high-nitrogen and Low $\mathrm{N}$ conditions for grain yield, leaf area, chlorophyll content, flowering time and other traits (Cai et al., 2012). Similarly, 147 QTLs were detected for root related traits in hydroponic condition and 72 QTLs found for each conditions (Li et al., 2015). Likewise, Luo et al., (2015) reported that about 212 QTLs detected for yield components and other agronomic traits under Low $\mathrm{N}$ condition, out of these, 21 consensuses QTL strongly induced for low-N tolerance and about 30 candidate genes were identified from other comparative estimated expression data. Moreover, 150 RILs were evaluated for agronomical and physiological traits and genotyped with marker under high-nitrogen (HN) and LN conditions.38 QTL detected for HN and 35 for LN, meanwhile 13 over lapping QTLs were detected under both nitrogen conditions (Kunhui et al., 2018), suggesting that common QTL/genes for controlling different traits under both conditions.

Genotype variation in NUE might be explained by nitrogen uptake and nitrogen utilization efficiency. This genetic variability was further confirmed during the detection of specific quantitative trait loci (QTL) for a high and Low N fertilization (Bertin and Gallais, 2000b). Similarly, Coque et al (2008) reported that QTLs for stay green in leaves and deep root result in increased $\mathrm{N}$ uptake from soil were coincident with loci controlling grain yield under low and high $\mathrm{N}$ levels. This may be due to pleiotropy or genetic linkage between loci controlling these phenotypic traits for NUE. Further explanation, N-uptake in grain filling can be related to leaf senescence suggesting that the more extended stay green, prolonging the capacity of the plant to absorb mineral nitrogen, better yields were expected from performed hybrids.

Furthermore, Li et al (2015) reported that clustered QTLs associated with NUE and related to root architecture traits expressed under low and high N environments. Moreover, 181 maize RILs were phenotyped and genotyped to detect QTLs for nitrogen use efficiency (NUE) and other related traits under high and low N conditions over 
two years and found that QTLs on chromosome 1 and 6 showed that consistent additive gene effects for grain yield per plant and NUE, as well as for biomass and nitrogen harvest index (Mandolino et al., 2018). Likewise, several QTLs for yield and its components, agronomic, physiological and with corresponding enzymes activity were detected on chromosome region (Gallais and Hirel, 2004), suggesting that predictable candidate genes or genes encoding enzymes that influencing NUE and for corresponding agronomic and/or physiological traits. Hirel et al., (2001) reported that recombinant inbred lines were analyzed for physiological traits such as nitrate content, nitrate reductase (NR), and glutamine synthetase (GS) activities. QTLs for yield and its components, genes encoding cytosolic GS were detected on chromosome 5 that explained high variation for kernel weight that also conceded for GS, NR activity, and nitrate content, suggesting that leaf nitrate accumulation and the reactions catalyzed by NR and GS are important for controlling nitrogen use efficiency in maize.

\section{Conclusion}

Multiple traits including morphological, physiological and yield components are associated with yield under Low $\mathrm{N}$ tolerance in maize. Breeding for Low $\mathrm{N}$ and drought have common traits indicating that common adaptive mechanism and possible to breed for both conditions. Contrary, genetic bases for breeding Low $\mathrm{N}$ reported. However, both additive and non-additive effects are important and possible to develop hybrids and OPV for Low $\mathrm{N}$ tolerance. Apart from this, some investigators reported that elite maize hybrids tolerant to random abiotic stress can be most efficiently selected under optimal and/or low-N conditions while low-N tolerant genotypes should be selected directly under low N. However, this idea as it is, I agreed with Mastrodomenico et al.,(2017) found that a few maize hybrid exhibited high yield performance under low and high $\mathrm{N}$ condition across environments, thus it likely good for subsistence farmers for maize production in Africa.

Multiple QTLs detected under Low N and high-nitrogen conditions for grain yield per plant, leaf area, leaf senescence, root, chlorophyll content, flowering time and physo-chemicals. Similarly, clustered QTLs detected that associated with NUE; stay green, related to root architecture and physiological traits under low and high $\mathrm{N}$ environments. However, a direct use of these detected QTLs has not been less achieved breeding for Low N tolerance in maize program, because of eQTLs. Thus, stable QTLs should be validated and fine mapping or GWAS should detect the candidate genes, i.e genes for which allelic variation should be identified for controlling NUE and, thus, these novel genes/ favorable alleles can be transferred to adaptive genotype under stress conditions.

\section{References}

Ajala SO, KlingJG. and Menkir A. 2012. Full-Sib family selection in maize populations for tolerance to low soil nitrogen. Journal of crop improvement, 26:.581-598.

Banziger M and Lafitte HR. 1997. Efficiency of secondary traits for improving maize for low-nitrogen target environments. Crop Science, 37, 1110-1117

Banziger M. Edmeades O, and Lafi tte HR. 1999. Selection for drought tolerance increases maize yields across a range of nitrogen levels. Crop Sci. 39:1035-1040

Bänziger M., Setimela P., Hodson D and Vivek B. 2004. Breeding for improved drought tolerance in maize adapted to southern Africa. Proceedings of the 4th International Crop Science Congress, 26 Sep.-1 Oct. 2004, Brisbane, Australia

Bertin P and Gallais A. 2000b. Physiological and genetic basis of nitrogen use efficiency in maize: II. QTL detection and coincidences. Maydica (in press)

Bello OB, Afolabi MS, Ige SA., Abdulmaliq SY, Azeez MA and Mahmud J. 2011. Yield response of diallelic crossed maize (Zea mays L.) genotypes to varying nitrogen regimes in Nigeria. Journal of Bio-Sciences, 19, 43-52

Belaw EF. 2002. Nitrogen metabolism and crop productivity. In Pessarakli eds. Handbook of Plant and Crop Physiology. Second edition. New York. Marcel Dekker Inc., 385-406

Cai H, Lu Y, Xie W, Zhu T, Lian X (2012c) Transcriptome response to nitrogen starvation in rice. J Biosci 37:731747

Chamarthi SK, Kumar A, Vuong T, Blair MW, Gaur PM, Nguyen HT, Varshney RK .2011 Trait mapping and molecular Breeding in legumes: concepts and examples in soybean, common bean and chickpea. In: Pratap A, Kumar J (eds) Biology and breeding of food legumes. CABI International, Oxfordshire, UK (in press).

Coque M, Martin A, Veyrieras JB, Hirel B and Gallais A, 2008. Genetic variation for N-remobilization and postsilking N-uptake in a set of maize recombinant inbred lines. 3. QTL detection and coincidences. Theoretical and Applied Genetics 117: 729-747

FAOSTAT . 2017. Statistical data bases and data-sets of the food and agricultural orga nization of the United nations. http://www. faostat. fao.org/default/aspx.

Gallais A and Hire B.2004., An approach to the genetics of nitrogen use efficiency in maize, Journal of Experimental Botany, 55, 295-306,

Hirel B., Bertin P., Quilleré I., Bourdoncle W., Attagnant C., Dellay C., Gouy A., Cadiou S., Retailliau C., Falque 
$\mathrm{M}$ and Gallais A., 2001. Towards a better understanding of the genetic and physiological basis for nitrogen use efficiency in maize. Plant Physiology, 125(3), pp.1258-1270

Ige SA., Bello O.B. and Alake O., 2018. Combining ability and heterosis of tolerance to low soil nitrogen in tropical maize cultivars derived from two breeding eras. Open Agriculture, 3; 339-346.

Kunhui He, Liguo Chang, Yuan Dong, Tingting Cui, Jianzhou Qu .Xueyan Liu . Shutu Xu . Jiquan Xue and Jianchao Liu. 2018. Identification of quantitative trait loci for agronomic and physiological traits in maize (Zea mays L.) under high nitrogen and low-nitrogen conditions. Euphytica 214:15

Li P, Chen F, Cai H, Liu J, Pan Q, Liu Z, Gu R, Mi G, Zhang F and Yuan L, 2015. A genetic relationship between nitrogen use efficiency and seedling root traits in maize as revealed by QTL analysis. Journal of Experimental Botany 66: 3175-3188

Luo B, Tang H, Liu H., Shunzong S., Zhang S., Wu L., Liu D and Gao S. 2015. Mining for low-nitrogen tolerance genes by integrating meta-analysis and large-scale gene expression data from maize. Euphytica, 206:117-131.

Mandolino CI, D’Andrea KE. Olmos SE, Otegui M.E and Eyhérabide GH.2018. Maize Nitrogen Use Efficiency: QTL Mapping in a US Dent x Argentine-Caribbean Flint RILs population. Maydica, 63(1), p.17

Mastrodomenico AT., Hendrix CC and Below FE, 2017. Genetic Variation of Nitrogen Use Traits Using Maize Expired Plant Variety Protection Germplasm.

Meseka, S.K., Menkir, A., Ibrahim, A.E.S. and Ajala, S.O., 2006. Genetic analysis of performance of maize inbred lines selected for tolerance to drought under low nitrogen. Maydica, 51(3), p.487.

Meseka SK., Menkir A., Ibrahim AS and Ajala SO.2013. Genetic analysis of maize inbred lines for tolerance to drought and low nitrogen. Jonares, 1:.29-36.

Mosisa W., Bänziger M., Friesen D., Erley SG, Horst WJ and Vivek BS.2008.. Relative importance of general combining ability and specific combining ability among tropical maize (Zea mays L.) inbreds under contrasting nitrogen environments. Maydica, 53, 279-288.

Noëlle MAH, Richard K., Vernon G., Martin YA., Laouali MN., Liliane TN and Godswill NN., 2017. Combining ability and gene action of tropical maize (Zea mays L.) inbred lines under low and high nitrogen conditions. Journal of Agricultural Science, 9:.222-235.

Niu J, Chen FJ, Mi GH, Li CJ and Zhang FS. 2007. Transpiration, and nitrogen uptake and flow in two maize (Zea mays L.) Inbred Lines as Affected by Nitrogen Supply. Annals of Botany 99: 153-160

Nyombayire A., Edema R., Asea G and Gibson P. 2011. Combining ability of maize inbred lines for performance under low nitrogen and drought stresses. In 10th African Crop Science Conference Proceedings, Maputo, Mozambique, 10-13 October 2011 (pp. 579-585). African Crop Science Society.

Segui-Simarro JM. 2015. Doubled haploidy in model and recalcitrant species. Frontiers in plant science.6

Shadakshari TV and Shanthakumar G. 2015: Evaluation of maize inbred lines for drought tolerance under contrasting soil moisture regimes. Karnataka J. Agric. Sci., 28: 142-146

Sinclair TR and Vadez V. 2002. Physiological traits for crop yield improvement in low N and P environments. Plant and Soil 245: 1-15

Tesfaye S, Zeleke H and Abakemal D: 2019. Combining ability of highland adapted maize (Zea mays L.) inbred lines for grain yield and yield related traits under optimum and low nitrogen conditions. Africa J.plant sc.13: $125-137$

Weber VS., Melchinger AE, Magorokosho C., Makumbi D., Bänziger M and Atlin GN.2012. Efficiency of managed-stress screening of elite maize hybrids under drought and low nitrogen for yield under rainfed conditions in Southern Africa. Crop Science, 52:.1011-1020.

Worku M, Bänziger M., Friesen D and Horst WJ. 2007. Nitrogen uptake and utilization in contrasting nitrogen efficient tropical maize hybrids. Crop Science, 47:.519-528.

Zambizib T and Mwambula C. 1997 The impact of drought and low soil nitrogen on maize production in the SADC region. pp. 29-34. In: G.O. Edmeades et al. (Eds.), Developing Droughtand Low N-Tolerant Maize. CIMMYT/UNDP. Mexico, D.F. 